\title{
HEAVY METAL CONCENTRATIONS IN WATER AND SEDIMENTS FROM AFFLUENTS AND EFFLUENTS OF MEDITERRANEAN CHILEAN RESERVOIRS
}

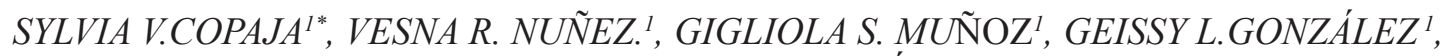 \\ IRMA VILA AND DAVID VÉLIZ.',3 \\ ${ }^{I}$ Departamento de Química, ${ }^{2}$ Departamento de Ciencias Ecológicas, ${ }^{3}$ Instituto de Ecología y Biodiversidad, Nucleo Milenio en Ecología y manejo sustentable de \\ Islas Oceánicas, Facultad de Ciencias. \\ Universidad de Chile. Casilla 653 Ñunoa, Santiago, Chile.
}

\begin{abstract}
RIVER flows have constant interaction between water and bed sediments; for this reason knowledge of the characteristics of the sediments is fundamental to understand water chemistry. This study determined the concentrations of heavy metals in water and sediments in the affluents and the effluents of the Mediterranean Chilean reservoirs Cogotí, Corrales, La Paloma, and Recoleta. We explore possible ecological risk and toxicity using the enrichment factor (EF), risk assessment code (RAC), threshold effect concentrations (TEC) and probable effect concentrations (PEC). The results showed that five metals: $\mathrm{Al}, \mathrm{Fe}, \mathrm{Cu}, \mathrm{Mn}$ and $\mathrm{Zn}$ out of the ten measured metals were detected in both surface water and the sediments. The risk assessment code (RAC) suggested that Fe represents a medium risk in the affluent of Cogotí Reservoir: $\mathrm{Cu}, \mathrm{Zn}$ and $\mathrm{Mn}$ represent a medium to high risk in all the dams and in both zones (affluents and effluents). The enrichment factor (EF) determined that the five metals were lithogenic. $\mathrm{Fe}, \mathrm{Cu}$, and $\mathrm{Mn}$ are the elements that present the greatest toxicity to microorganisms in these aquatic systems.
\end{abstract}

Key words: Heavy metals, dams, enrichment factor, sediment, risk assessment code.

\section{INTRODUCTION}

RIVER flows have constant interaction between water and bed sediments; for this reason knowledge of the characteristics of the sediments is fundamental to understand water chemistry. It is known that this interaction may solubilize or capture compounds that may be bio-available. One effect of this interaction is the possible pollution into the rivers by the presence of compounds or elements coming from human activities. It is estimated that currently over one million different substances are introduced in natural water discharges from anthropogenic use ${ }^{1}$. Many of them are not considered toxic, but they can alter the organoleptic characteristics of water or severely disrupt the ecosystem ${ }^{2}$. Some of the chemicals are potentially toxic, such as heavy metals including: $\mathrm{Al}, \mathrm{As}, \mathrm{Cd}, \mathrm{Cu}, \mathrm{Cr}, \mathrm{Hg}, \mathrm{Mn}, \mathrm{Ni}, \mathrm{Pb}$ and $\mathrm{Zn}$, even though some of these do not correspond to the exact definition of what is considered a heavy metal ${ }^{3}$.

Because heavy metals are not biodegradable, they usually are not removed from aquatic ecosystems by natural processes ${ }^{4-6}$, therefore heavy metals are of great significance as indicators of the ecological quality of all water flow, due to their toxicity, persistence and bio-accumulative behavior ${ }^{7,8}$ The contribution of these metals to the hydrological cycle comes from different sources, the most important being of lithogenic or geochemical origin. However, at present their greatest concentration is due to human activity, namely mining, agriculture, industrial processes and household waste ${ }^{9}$. Therefore, an important part of the heavy metals in the water may be related to human activities ${ }^{10,11}$. This human activity has often led to the transformation of the water of rivers, lakes and coasts into waste deposits; natural balance is severely disturbed and in many cases totally $\operatorname{lost}^{4}$.

Once heavy metals enter the aquatic environment they generally show affinities to bind to suspended matter and thus to accumulate in sediments through sedimentation, mainly in rivers, lakes and seas ${ }^{4,12}$. These elements can easily move from the solid to liquid phase of water and vice versa following changes in both the biotic and abiotic components. The metals in the sediments may re-solubilize in different chemical forms due to changes in environmental conditions such as $\mathrm{pH}$, redox potential (Eh), dissolved oxygen and presence of organic carbon ${ }^{13-16}$. The analysis of heavy metals in sediments allows us to detect contamination and also provides information on the critical areas of aquatic systems $\mathrm{s}^{1,7,9,17,19,20 .}$

Bioavailability of metals in sediments has a direct impact on some aquatic species, many of which can accumulate high concentrations of metals that can cause chronic effects on their populations ${ }^{21}$. For this reason these pollutants are among the most frequently monitored using standard analytical techniques for extraction and quantification. Since the 1980s, many efforts have been undertaken around the world to measure and characterize the behavior and distribution of heavy metals in sediments ${ }^{22-24}$.
Given the great importance of hydrology, alterations in the flow of rivers caused by humans have serious consequences ${ }^{25}$, increasing recognition that anthropogenic changes in rivers such as construction of dams, river diversions or channel modifications have significant long-term consequences for water supply, water quality, aquatic ecosystems and sediment budgets ${ }^{26,27}$. Among these interventions dams are one of the most dramatic and widespread impacts of humans on the natural environment ${ }^{28}$. Dams were primarily built to supply humans with fresh water, either for direct consumption or for agriculture. Later, reservoirs were also built to produce hydroelectric power and to regulate river flow $^{29}$. It has been estimated that in the world at present there are around 45,000 dams with a water column depth of more than 15 meters $^{30}$. However, there are no systematic studies on the influence of dams on the distribution of heavy metals in sediment, considering that a dam alters the free flow of a river to the sea; only recently has work begun in which the seasonal distribution of heavy metals is studied in a dam ${ }^{31}$.

Considering that there are dams in a number of rivers in Chile producing disruption of free water flow, and that mineral salts may accumulate in the zone of the dam ${ }^{32}$, the goal of this study was to determine the concentrations of heavy metals in both water and sediments as a labile fraction (soluble, exchangeable or bonded to carbonate) and pseudo-totals in the affluent and effluent of four reservoirs (Cogotí, Corrales, La Paloma, and Recoleta). Additionally, we estimated the possible ecological risk from sediment by calculating the enrichment factor $(E F)^{33}$, risk assessment code $(\mathrm{RAC})^{34-35}$, threshold effect concentration (TEC) and the probable effect concentration (PEC) ${ }^{36}$.

\section{EXPERIMENTAL}

\subsection{Sampling area}

Mediterranean rivers from $30^{\circ} \mathrm{S}$ to $34^{\circ} \mathrm{S}$ in central Chile were studied in order to determine differences in the effluents and affluents of the large reservoirs. These reservoirs were built at different times; three of them are located in the Limarí River basin: Recoleta (built in 1934), Cogotí (built in 1938) and La Paloma (built in 1966); all are used exclusively for agricultural irrigation. The Corrales dam is located in the Choapa River basin; it was constructed in 2001 for irrigation of the Choapa valley (Fig. 1). Sampling was conducted in August 2010 in the high flow season (winter), from six sites in the affluent and six in the effluent separated by 0.5 to $2 \mathrm{~km}$.

\subsection{Sampling analyses}

Measurements of $\mathrm{pH}$, electrical conductivity (EC) and redox potential (Eh) of the water and sediments were made in situ using a portable multimeter (VWR multi 340i).

2.1.1 Water analysis

$200 \mathrm{~mL}$ of water was sampled to quantify dissolved oxygen (DO) using 
the Winkler method. A $1 \mathrm{~L}$ sample was obtained from the same sites to quantify total phosphorus (TP) following a protocol described before ${ }^{37}$.

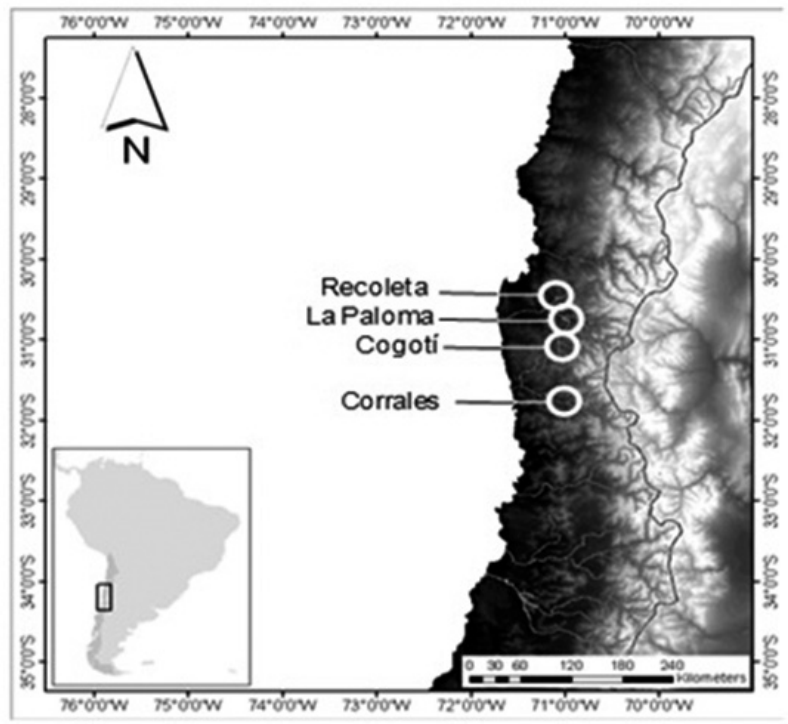

Figure 1. Location of sampling sites in the Mediterranean Rivers of Chile.

\subsubsection{Sediment analysis}

In each site, three samples of $1 \mathrm{~kg}$ of sediment were collected in polyethylene flasks according to the protocol described before ${ }^{38}$, which requires collecting samples with a plastic shovel from the top of the superficial sediment zone. Samples were brought to the laboratory and stored at $4{ }^{\circ} \mathrm{C}$. The three samples were then pooled to obtain the necessary quantity of $<0.63 \mu \mathrm{m}$ material. In the laboratory, the Walkley-Black method was used to determine organic carbon content and water soluble phosphorus was determined by the Olsen method ${ }^{39}$, 40.

\subsubsection{Heavy metals analysis}

The heavy metals analyzed in this study were: $\mathrm{Al}, \mathrm{Cd}, \mathrm{Cr}, \mathrm{Cu}, \mathrm{Fe}, \mathrm{Mn}, \mathrm{Mo}$, $\mathrm{Ni}, \mathrm{Pb}$ and $\mathrm{Zn}$. To determine differences in these metal concentrations, samples from affluents were compared to those obtained in the effluents. Water was collected in $1 \mathrm{~L}$ vials, filtered and fixed with $2 \%$ nitric acid (suprapur Merck). For sediments, metals were obtained from the $3 \mathrm{~kg}$ sampled per site. The labile fraction of the sediments was obtained by stirring $0.5 \mathrm{~g}$ of the pellet with 40 $\mathrm{mL}$ acetic acid (Merck p.a.) $0.11 \mathrm{~mol} \mathrm{~L}^{-1}$ for $16 \mathrm{~h}$, and then the samples were centrifuged at $3500 \mathrm{rpm}$ for $30 \mathrm{~min}$. The pseudo-total fraction was obtained by digesting $1 \mathrm{~g}$ of sediment with $10 \mathrm{~mL}$ of nitric acid (suprapur Merck) in a high resolution microwave oven (MarsX press) using the following conditions: power $800 \mathrm{~W}$; tower $100-5$; time $11 \mathrm{~min}$; ; temperature $175{ }^{\circ} \mathrm{C}$, maintenance $15 \mathrm{~min}$.; cooling $15 \mathrm{~min}$. This was based on EPA method 3051: Microwaveassisted acid digestion of sediments, sludge, soils, and oils. Finally, the samples were kept cold $\left(4^{\circ} \mathrm{C}\right)$ for posterior analysis.

Standard solutions for heavy metals were prepared from Titrisol 1000 $\mathrm{mgL}^{-1}$ (Merck); samples were determined using an atomic absorption spectrophotometer (AAS) (Shimadzu spectrophotometer 6800, ASC-6100 auto sampler and graphite furnace GFA-EX7). The following wavelength lines were used: $\mathrm{Cu}=324.7 \mathrm{~nm} ; \mathrm{Al}=309.3 \mathrm{~nm} ; \mathrm{Cr}=357.9 \mathrm{~nm} ; \mathrm{Cd}=228.8 \mathrm{~nm} ; \mathrm{Fe}=$ $248.3 \mathrm{~nm} ; \mathrm{Mn}=279.5 \mathrm{~nm} ; \mathrm{Ni}=232.0 \mathrm{~nm} ; \mathrm{Pb}=217.0 \mathrm{~nm} ; \mathrm{Mo}=313.3 \mathrm{~nm}$ and $\mathrm{Zn}=213.8 \mathrm{~nm}$.

\subsubsection{Analytical method validation and quality control}

To assure the accuracy of the data reported, recovery experiments were performed using standard reference material for water and sediments (ERMCA615 and BCR-320R, respectively). The concentration ranges were based on the limit of detection (LOD) and the limit of quantification (LOQ) for each metal. The experiment was performed in triplicate; a calibration curve was obtained to determine the linear relationship between absorbance and metal concentration in the concentration range used. Reagent blanks were prepared and measured in the same way as samples.

\subsubsection{Statistical analysis}

To determine differences in $\mathrm{pH}$, electrical conductivity and redox potential between dams and sites (affluents and effluents) in water and sediments, twoway ANOVA permutations were performed using $\mathrm{R}$ software ${ }^{41}$. A principal components analysis (PCA) was used to determine the relationships between metals in water, sediment and environmental variables.

\section{RESULTS AND DISCUSSION}

\subsection{Parameters for analytical methods}

Tables 1 and 2 show the analytical parameters from the validation of methods for water and sediments.

Table 1. Analytical parameters for determination of total heavy metals in water (Water Reference Material: ERM-CA615).

\begin{tabular}{|c|c|c|c|c|}
\hline Metals & $\begin{array}{c}\text { LOD } \\
\left(\mathbf{m g L}^{1}\right)\end{array}$ & $\begin{array}{c}\mathbf{L Q D}_{\mathbf{1}} \\
\mathbf{( m g L}^{-} \mathbf{)}\end{array}$ & $\begin{array}{c}\text { Percent } \\
\text { Recovery }\end{array}$ & Linearity $\left.\mathbf{R}^{2}\right)$ \\
\hline $\mathrm{Fe}$ & 0.51 & 0.94 & $90 \pm 2$ & 0.9995 \\
\hline$* \mathrm{Cu}$ & 0.0006 & 0.0010 & $101 \pm 4$ & 0.9988 \\
\hline $\mathrm{Mn}$ & 0.37 & 0.57 & $102 \pm 3$ & 0.9981 \\
\hline $\mathrm{Zn}$ & 0.08 & 0.09 & $103 \pm 3$ & 0.9995 \\
\hline $\mathrm{Al}$ & 0.42 & 0.66 & $100 \pm 5$ & 0.9981 \\
\hline $\mathrm{Cd}$ & 0.03 & 0.02 & $112 \pm 6$ & 0.9994 \\
\hline $\mathrm{Cr}$ & 0.07 & 0.11 & $102 \pm 2$ & 0.9991 \\
\hline $\mathrm{Ni}$ & 0.06 & 0.09 & $108 \pm 6$ & 0.9994 \\
\hline $\mathrm{Pb}$ & 0.07 & 0.13 & $104 \pm 6$ & 0.9991 \\
\hline$* \mathrm{Mo}$ & 0.0009 & 0.0012 & $101 \pm 5$ & 0.9974 \\
\hline
\end{tabular}

* Metals measured by electrothermal atomization

The percent of recovery were satisfactory and indicated a good agreement between our data and the reference values. For water the highest detection limits and quantification limits were for $\mathrm{Al}$, while the lowest limits corresponded to $\mathrm{Cu}$ and $\mathrm{Mo}$, both determined by thermal electro-atomization (graphite furnace). For sediment $\mathrm{Al}$ also presented the highest limits of detection and quantification in both fractions, while the lowest limits were for $\mathrm{Cd}$.

\subsection{Physicochemical Characterization of water and sediment}

Table 3 shows the physical and chemical characteristics of surface water and sediment in affluents and effluents of the reservoirs studied. The $\mathrm{pH}$ was alkaline in all the systems; it was most alkaline $(\mathrm{pH}=8.63)$ in the surface water from the effluent of the La Paloma reservoir and least alkaline $(\mathrm{pH}=7.27)$ in the effluent of the Corrales reservoir. Differences in $\mathrm{pH}$ could be related to the oxidation-reduction potential; these parameters define the existence of soluble chemical species or allow metal solubilization from the sediments ${ }^{42}$

Significant differences in $\mathrm{pH}$ were detected for both sediments and water. In the case of water, a difference was detected in the interaction between dam and site (affluent and effluent) $(p=0.001$, Fig. 2a) showing that the effluent of Corrales dam presented lower values compared to the other sites $(\mathrm{p}<0.005$, Fig. 2b). 
Table 2. Analytical parameters for determination of soluble and total heavy metals in sediment (Sediment Reference Material: BCR- 320R).

\begin{tabular}{|c|c|c|c|c|c|c|c|}
\hline \multirow{2}{*}{ Metals } & \multicolumn{2}{|c|}{ LOD(mgL $^{-}$) } & \multicolumn{2}{c|}{ LQD(mgL } & \multicolumn{2}{c|}{ Percent Recovery } & Linearity \\
\hline & Total fraction & Soluble fraction & Total fraction & Soluble fraction & Total fraction & Soluble fraction & $\mathbf{R}^{2}$ \\
\hline $\mathrm{Fe}$ & 0.26 & 0.10 & 0.50 & 0.16 & $90 \pm 3$ & $89 \pm 2$ & 0.9984 \\
\hline $\mathrm{Cu}$ & 0.04 & 0.05 & 0.07 & 0.10 & $82 \pm 1$ & $80 \pm 4$ & 0.9970 \\
\hline $\mathrm{Mn}$ & 0.04 & 0.03 & 0.08 & 0.04 & $89 \pm 2$ & $83 \pm 6$ & 0.9990 \\
\hline $\mathrm{Zn}$ & 0.05 & 0.13 & 0.09 & 0.25 & $91 \pm 6$ & $90 \pm 5$ & 0.9991 \\
\hline $\mathrm{Al}$ & 1.82 & 1,80 & 4.27 & 3.89 & $82 \pm 2$ & $84 \pm 4$ & 0.9983 \\
\hline $\mathrm{Cd}$ & 0.01 & 0.02 & 0.02 & 0.03 & $87 \pm 4$ & $85 \pm 5$ & 0.9995 \\
\hline $\mathrm{Cr}$ & 0.20 & 0.11 & 0.36 & 0.19 & $95 \pm 5$ & $92 \pm 2$ & 0.9968 \\
\hline $\mathrm{Ni}$ & 0.08 & 0.12 & 0.22 & 0.17 & $100 \pm 1$ & $98 \pm 1$ & 0.9988 \\
\hline $\mathrm{Pb}$ & 0.18 & 0.19 & 0.26 & 0.23 & $102 \pm 3$ & $100 \pm 3$ & 0.9960 \\
\hline $\mathrm{Mo}$ & 0.42 & 0.31 & 0.80 & 0.65 & $89 \pm 1$ & $85 \pm 6$ & 0.9961 \\
\hline
\end{tabular}

Table 3. pH, conductivity (EC) and redox potential (Eh) measured in superficial water and sediments

\begin{tabular}{|c|c|c|c|c|c|c|c|}
\hline \multirow{2}{*}{ Dam } & \multirow{2}{*}{ Zone } & \multicolumn{3}{|c|}{ Water } & \multicolumn{3}{c|}{ Sediment } \\
\cline { 3 - 8 } & & $\mathbf{p H}$ & $\mathbf{E C}\left(\mathbf{m S c m} \mathbf{- 1}^{-1}\right.$ & $\mathbf{E h} \mathbf{( m V )}$ & $\mathbf{p H}$ & $\left.\mathbf{E C}(\mathbf{d S m})^{-1}\right)$ & $\mathbf{E h}(\mathbf{m V})$ \\
\hline \multirow{3}{*}{ Cogotí } & Affluent & $8.37 \pm 0.21$ & $0.31 \pm 0.10$ & $88 \pm 12$ & $7.42 \pm 0.51$ & $0.32 \pm 0.13$ & $32 \pm 21$ \\
\cline { 2 - 8 } & Effluent & $8.45 \pm 0.48$ & $0.24 \pm 0.06$ & $92 \pm 27$ & $7.66 \pm 0.46$ & $0.21 \pm 0.07$ & $40 \pm 21$ \\
\hline \multirow{2}{*}{ La Paloma } & Affluent & $8.37 \pm 0.36$ & $0.34 \pm 0.01$ & $93 \pm 6$ & $7.69 \pm 0.34$ & $0.37 \pm 0.03$ & $44 \pm 21$ \\
\cline { 2 - 8 } & Effluent & $8.63 \pm 0.08$ & $0.34 \pm 0.01$ & $99 \pm 4$ & $7.57 \pm 0.38$ & $1.13 \pm 0.90$ & $37 \pm 24$ \\
\hline \multirow{3}{*}{ Recoleta } & Affluent & $8.43 \pm 0.06$ & $0.41 \pm 0.13$ & $50 \pm 19$ & $8.43 \pm 0.06$ & $0.41 \pm 0.13$ & $89 \pm 4$ \\
\cline { 2 - 8 } & Effluent & $8.29 \pm 0.03$ & $1.60 \pm 0.90$ & $36 \pm 3$ & $8.29 \pm 0.03$ & $1.60 \pm 0.90$ & $80 \pm 2$ \\
\hline \multirow{2}{*}{ Corrales } & Affluent & $8.24 \pm 0.34$ & $0.29 \pm 0.02$ & $83 \pm 20$ & $7.96 \pm 0.12$ & $0.33 \pm 0.06$ & $66 \pm 6$ \\
\cline { 2 - 8 } & Effluent & $7.30 \pm 0.16$ & $0.24 \pm 0.06$ & $30 \pm 8$ & $7.27 \pm 0.26$ & $0.28 \pm 0.15$ & $26 \pm 14$ \\
\hline
\end{tabular}

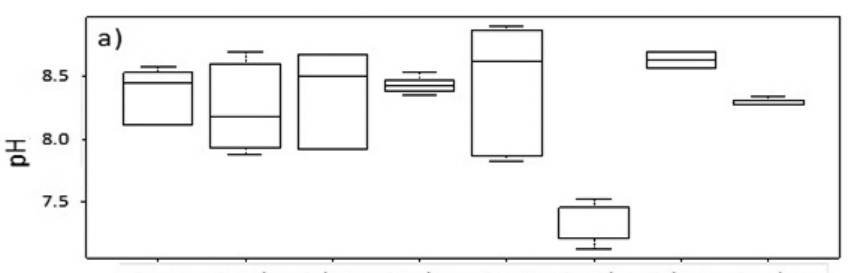

Cogoti Corrales Paloma Recoleta Cogoti Corrales Paloma Recoleta

Affluent Effluent

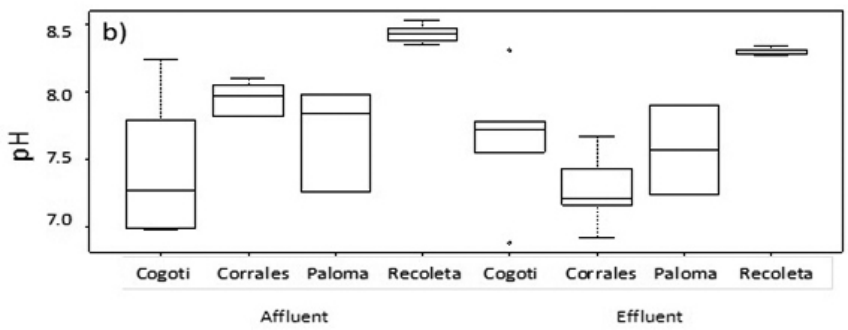

Figure 2. Boxplot of $\mathrm{pH}$ in sediments (a) and water (b).

Electrical conductivity (EC) was highest in the effluent of the Recoleta dam for both water and sediment, while the lowest value was measured in the effluent of Cogoti (Table 3). The ANOVA performed for EC showed a significant effect of the interaction of dams and site for both water and sediment ( $p<0.001$ and $p=0.002$, respectively). In the water column, the effluent of the Recoleta dam showed higher values ( $p<0.005$, Fig.3a). In the case of the sediment, the effluent from La Paloma had higher EC values than the other sites
( $p<0.005$, Fig. 3b). Low EC values indicate low saline waters and sediments (EC 0.0-3.0 dS m $\mathrm{m}^{-1}$ ); values $>3 \mathrm{dSm}^{-1}$ indicate salinity problems. In this study the highest values were found in the effluent of Recoleta reservoir (surface water and sediment, $1.60 \pm 0.90 \mathrm{dS} \mathrm{m}^{-1}$ ) and the effluent of La Paloma $1.13 \pm$ $0.90 \mathrm{dS} \mathrm{m}^{-1}$ indicating that these two sites must be considered to have moderate salinity (quality $\mathrm{C} 1$ ).
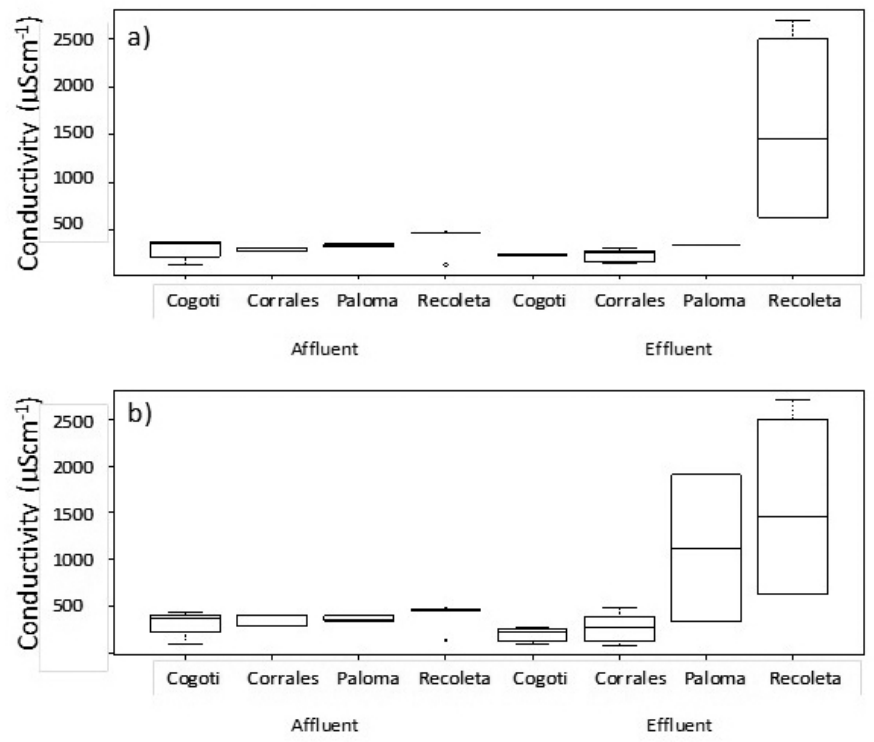

Figure 3. Boxplot of for EC in sediments (a) and water (b). 
Eh values indicate oxidant conditions in water and sediments. The ANOVA performed for Eh showed a significant effect of the interaction in both water and sediments $(p<0.001$ and $p=0.008$ respectively). In the water column, the effluent of Corrales and Recoleta showed lower values compared to the other sites ( $p<0.005$, Fig. $4 a)$, in the sediments, the effluent and affluent of Recoleta showed the highest values ( $<<0.005$, Fig. $4 b)$.
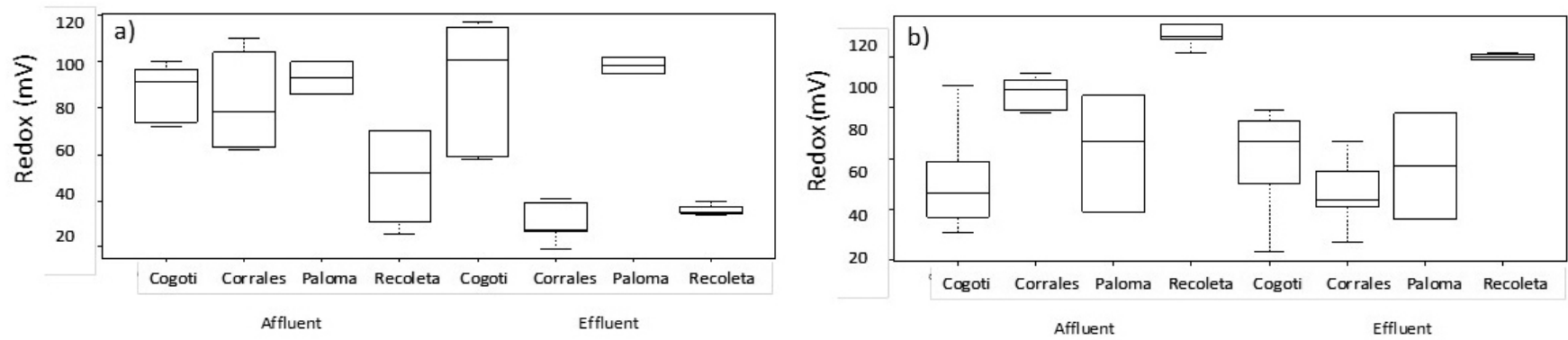

Figure 4. Boxplot of for Eh in sediments (a) and water (b).

Table 4 shows the concentrations of dissolved oxygen and total phosphorus in surface water and percentages of organic carbon and soluble phosphorus in the sediment. In the case of the oxygen no significant differences were found between dams or sites $(\mathrm{p}>0.05)$.

There were not large differences in \%OC between dams and between affluents and effluents except in the effluent of Recoleta reservoirs. This could be explained by the proximity of the city of Ovalle, which may be a source of urban waste; the same explication applies for the high value of soluble phosphorous. Dissolved oxygen values did not show large differences between reservoirs and affluents-effluents, indicating oxygenated systems. The effluent of the Corrales reservoir was the exception, which showed the lowest value $\left(7.34 \mathrm{mgL}^{-1}\right)$. There were differences in total $\mathrm{P}$ between and among reservoir tributaries and effluents. Total phosphorous in water showed the highest values in the effluent of Corrales, which may be explained because this sample was collected near a camping site. Water-soluble phosphorous in sediment showed the highest value in the effluent of La Paloma, probably this is due to use of fertilizers (Table 4).

Table 4. Summary of the chemical characteristics measured in water and sediments. Each value represents the mean (and standard deviation) of six samples. $<\mathrm{LD}=$ below detection limit

\begin{tabular}{|c|c|c|c|c|c|}
\hline \multirow{3}{*}{ Dam } & \multirow{2}{*}{ Zone } & \multicolumn{2}{|c|}{ Water } & \multicolumn{2}{|c|}{ Sediments } \\
\cline { 3 - 6 } & & $\begin{array}{c}\text { Dissolved oxygen } \\
\left(\mathbf{m g L}^{-1}\right)\end{array}$ & $\begin{array}{c}\text { Total Phosphorous } \\
\left(\mathbf{m g L}^{-1}\right)\end{array}$ & $\begin{array}{c}\text { Organic Carbon } \\
\mathbf{( \% )}\end{array}$ & $\begin{array}{c}\text { Soluble Phosforous } \\
\left(\mathbf{m g k g}^{-1}\right)\end{array}$ \\
\hline \multirow{3}{*}{ Cogotí } & Affluent & $10.20 \pm 2.06$ & $10.21 \pm 5.49$ & $1.63 \pm 0-43$ & $6.81 \pm 0.34$ \\
\cline { 2 - 6 } & Effluent & $1234 \pm 1.26$ & $29.37 \pm 2.93$ & $1.29 \pm 0.48$ & $5.24 \pm 0.23$ \\
\hline \multirow{3}{*}{ La Paloma } & Affluent & $10.20 \pm 0.58$ & $15.65 \pm 5.34$ & $1.51 \pm 0.33$ & $15.0 \pm 3.56$ \\
\cline { 2 - 6 } & Effluent & $10.56 \pm 0.42$ & $3.82 \pm 1.05$ & $1.14 \pm 0.13$ & $48.08 \pm 8.96$ \\
\hline \multirow{3}{*}{ Recoleta } & Affluent & $9.96 \pm 1.20$ & $<\mathrm{LD}$ & $1.92 \pm 1.06$ & $11.9 \pm 2.65$ \\
\cline { 2 - 6 } & Effluent & $11.07 \pm 0.54$ & $15.89 \pm 1.46$ & $8.43 \pm 1.60$ & $49.7 \pm 6.20$ \\
\hline \multirow{3}{*}{ Corrales } & Affluent & $11.15 \pm 2.20$ & $7.01 \pm 0.71$ & $2.24 \pm 0.45$ & $5.19 \pm 0.12$ \\
\cline { 2 - 6 } & Effluent & $7.34 \pm 0.36$ & $40.44 \pm 35.33$ & $1.85 \pm 0.23$ & $9.09 \pm 0.45$ \\
\hline
\end{tabular}

\subsection{Heavy metal determination in water}

The analysis of heavy metals in surface water, labile fraction and pseudototal of sediments showed values above the detection limit for five metals $(\mathrm{Al}, \mathrm{Cu}, \mathrm{Fe}, \mathrm{Mn}$ and $\mathrm{Zn}$ ), thus the Figures and Tables show results only for these elements. We found no differences in most metal concentrations between affluents and effluents, indicating that the reservoirs do not act as a filter ${ }^{43,44}$.

Metal concentrations in surface water were higher than in the soluble fraction of the sediments in both tributaries and effluents. The highest concentrations found in surface water were $\mathrm{Mn}>\mathrm{Fe}>\mathrm{Al}>\mathrm{Cu}>\mathrm{Zn}$. There are no studies of heavy metals in surface waters in affluent and effluent of reservoirs. Thus we can only compare with other basins, for instance in thirteen sites of the basin of the river Ebro (Spain ) Cu values ranged from 3.68 - $94.6 \mu \mathrm{gL}^{-1} ; \mathrm{Mn}$ from 2.41 $-1227 \mu \mathrm{gL}^{-1} ; \mathrm{Zn}$ from $<0.2-120 \mu \mathrm{gL}^{-1} ; \mathrm{Al}$ and Fe were not measured in this study $^{45}$. A better comparison because of geographical similarity is the Choapa River basin (Chile); Al: 71.1-357; Cu: 2.45-65.1; Fe: 81.5-222; Mn: 10.3-70.6; $\mathrm{Zn}: 13.5-31.2$. Only the high values of $\mathrm{Cu}, \mathrm{Mn}$ and $\mathrm{Zn}$ from the Ebro basin are near the values of the metals in the reservoirs; the same is true comparing with those of the Choapa river basin except for $\mathrm{Mn}$, which showed considerably higher values. This might be explained by the presence of high concentrations of manganese carbonate, which is solubilized when the $\mathrm{pH}$ is decreased for sample preservation ${ }^{46-48}$.

\subsection{Heavy metal determinations in sediment}

In all reservoirs, both in affluents and effluents the pseudo-total fraction from sediment was higher, indicating that this fraction has mainly lithogenic contributions. The highest concentrations of the total fraction were those of $\mathrm{Al}$ and $\mathrm{Fe}$ (7097 to 37769 and 6785 to $42567 \mathrm{mg} \mathrm{g}^{-1}$, respectively). The labile or soluble fraction of the sediment was lower in all situations or under detection limits (Table 6). These results should be considered remembering that the solubility of metals depends on the characteristics of the water system such as $\mathrm{pH}$ and $\mathrm{Eh}^{42}$. Heavy metals tend to form partnerships with minerals by ion exchange phenomena, complexes or precipitates (carbonates, sulfates, phosphates, etc.) and with organic substances by adsorption, chelation and others $^{49-51}$. 
Table 5. Summary of the heavy metal concentrations $\left(\mu \mathrm{gL}^{-1}\right)$ in surface water. Each value represents the mean of six samples. $<\mathrm{LD}=$ below the detection limit.

\begin{tabular}{|c|c|c|c|c|c|c|}
\hline Dam & Zone & Al & $\mathrm{Cu}$ & $\mathrm{Fe}$ & Mn & $\mathrm{Zn}$ \\
\hline \multirow{2}{*}{ Corrales } & Affluent & 118 & 69 & 253 & 1359 & 74 \\
\hline & Efluent & 167 & 71 & 355 & 1951 & 23 \\
\hline \multirow{2}{*}{ Recoleta } & Affluent & 213 & 70 & 199 & 1255 & 49 \\
\hline & Effluent & 170 & 60 & 198 & 1663 & 33 \\
\hline \multirow{2}{*}{ Cogotí } & Affluent & 155 & 64 & 216 & 1279 & 37 \\
\hline & Effluent & 182 & 54 & 237 & 1434 & 19 \\
\hline \multirow{2}{*}{ La Paloma } & Affluent & 173 & 68 & 326 & 1309 & 26 \\
\hline & Effluent & 218 & 69 & 183 & 2372 & 13 \\
\hline
\end{tabular}

It is difficult to compare these values with those reported in other studies, mainly due to the large geographical and geological differences. Determination of heavy metals in sediments of the Mapocho River ${ }^{52}$ indicated concentrations in the total fraction of $\mathrm{Cu}$ between $209 \pm 12$ and $2850 \pm 490$ and $\mathrm{Zn:} 607 \pm 240$ and $1290 \pm 370 ; \mathrm{Al}, \mathrm{Fe}$ and $\mathrm{Mn}$ were not determined in this study. Analysis of metals in the total fraction of sediments of the Aguanilpa Reservoir (Mexico), reported that $\mathrm{Al}$ values were found between 22100 and 7760; Fe: 15900 and 4740; $\mathrm{Cu}: 60.8$ and $0.79 ; \mathrm{Zn}: 51.8$ and $14.8 \mu \mathrm{gg}^{-1}$; $\mathrm{Mn}$ was not determined in this study ${ }^{31}$. A better comparison because of geographical similarity corresponds to the determination of heavy metals in the basin of the Choapa River (winter season); the values found for $\mathrm{Al}$ ranged from 15649-6200; Fe: 3462321656; Cu: 4814-70; Mn: 1671-356; Zn: 91-33 ${ }^{46,51}$.

$\mathrm{Cu}$ and $\mathrm{Zn}$ concentrations found in sediment (total fraction) in the Mapocho River are slightly higher than those found in our study, indicating further contamination of these sediments. Values reported in the Aguanilpa
Reservoir were relatively similar to ours for $\mathrm{Al}$ and $\mathrm{Fe}$, while for $\mathrm{Cu}$ and $\mathrm{Zn}$ these values were lower; the authors concluded that this reservoir could be considered unpolluted. The comparison with the values of the five metals determined in the Choapa River basin indicates that the values found were generally slightly lower than those determined in our study, which could be due mainly to the hydrodynamic sediment conditions, i.e. without much sediment movement with little ability to transfer, while in the Choapa basin there is an increased movement of sediment due to the slope of the river ${ }^{46}$.

In the soluble faction $\mathrm{Al}$ was under the detection limit in the most of sites, except in the affluent of the Recoleta reservoir $\left(230 \mathrm{ugg}^{-1}\right)$ and the tributary of Cogotí $\left(359 \mathrm{ugg}^{-1}\right)$ reservoir. Al concentration was higher even when the $\mathrm{pH}$ of the water would not solubilize it. Since the ion Al (III) is present only at $\mathrm{pH}$ $<4^{43}$, it is unlikely to find $\mathrm{Al}$ in significant concentrations in water at alkaline $\mathrm{pH}$.

Table 6. Summary of the heavy metal concentrations in soluble and total fractions of sediments $\left(\mu \mathrm{gg}^{-1}\right)$. Each value represents the mean of six samples. $<$ LD $=$ below the detection limit.

\begin{tabular}{|c|c|c|c|c|c|c|c|c|c|c|c|}
\hline \multirow{3}{*}{ Dam } & \multirow{3}{*}{ Zone } & \multicolumn{2}{|c|}{ Al } & \multicolumn{2}{|c|}{$\mathbf{C u}$} & \multicolumn{2}{|c|}{$\mathbf{F e}$} & \multicolumn{2}{|c|}{ Mn } & $\mathbf{Z n}$ & \\
\hline & & \multicolumn{2}{|c|}{ Sediment } & \multicolumn{2}{|c|}{ Sediment } & \multicolumn{2}{|c|}{ Sediment } & \multicolumn{2}{|c|}{ Sediment } & \multicolumn{2}{|c|}{ Sediment } \\
\hline & & Soluble & Total & Soluble & Total & Soluble & Total & Soluble & Total & Soluble & Total \\
\hline \multirow{2}{*}{ Corrales } & Affluent & $<\mathrm{LD}$ & 37169 & 79.2 & 252 & 362 & 37694 & 725 & 1289 & 17 & 150 \\
\hline & Efluent & $<\mathrm{LD}$ & 30357 & 90.2 & 230 & 303 & 32334 & 1306 & 1870 & 8 & 139 \\
\hline \multirow{2}{*}{ Recoleta } & Affluent & 230 & 27468 & 79.2 & 252 & 15 & 30942 & 893 & 2234 & 60 & 264 \\
\hline & Effluent & $<\mathrm{LD}$ & 7097 & 90.2 & 220 & 14 & 6785 & 678 & 1617 & 13 & 275 \\
\hline \multirow{2}{*}{ Cogotí } & Affluent & 359 & 36480 & 19.2 & 110 & 217 & 29933 & 687 & 1296 & 211 & 299 \\
\hline & Effluent & $<\mathrm{LD}$ & 36487 & 50.7 & 244 & 22 & 42567 & 1766 & 2616 & 22 & 144 \\
\hline \multirow{2}{*}{$\begin{array}{c}\text { La } \\
\text { Paloma }\end{array}$} & Affluent & $<\mathrm{LD}$ & 22682 & 4.5 & 71 & 21 & 24803 & 506 & 965 & 21 & 129 \\
\hline & Effluent & $<\mathrm{LD}$ & 35333 & 4.8 & 126 & 15 & 33766 & 8508 & 8969 & 15 & 118 \\
\hline
\end{tabular}

The soluble fraction of the other metals studied ranged between $5 \%$ and $70 \%$, depending on the reservoir and the zone (Figure 5). Sequential extraction studies performed in the Choapa River basin show similar behavior ${ }^{51}$. The mobility and bioavailability of metals varied significantly with sediment properties, organic carbon, carbonates, $\mathrm{pH}$, redox potential, phosphates and water flow. The soluble fraction was extracted with $0.11 \mathrm{M}$ acetic acid, which gives a $\mathrm{pH}=2,9$. This indicates that when the $\mathrm{pH}$ of the sediment-water system is decreased, these metals become highly available for the biota, and this could liberate them in the water. The high percentage of $\mathrm{Mn}$ in weakly-bound fractions was probably due to its special affinity for carbonate, indicating that considerable amounts of Mn may be released into water following a non-exchange process and dissociation of the Mn-carbonate phase if sediment conditions became more $\mathrm{acid}^{39}$. $\mathrm{Cu}$ and $\mathrm{Zn}$ are species, besides forming compounds with carbonate which can be released, can be easily exchanged in the adsorption sites of the sediments. Fe solubilized little because at this $\mathrm{pH}(\mathrm{pH}=2,9)$ this element may be precipitate as iron hydroxylated species, so the highest concentration of Fe in the Corrales reservoir released in both zones could be due to an extra contribution in this site.

The following figures show the percentages of the soluble fraction of the total sediment fraction for $\mathrm{Cu}, \mathrm{Fe}, \mathrm{Al}, \mathrm{Mn}$ and $\mathrm{Zn}$ in the affluent and effluent of the four reservoirs.

\subsection{Ecological risk and toxicity}

3.5.1 Risk assessment code (RAC)

The risk assessment code (RAC) uses the percentage fraction of metals that are exchangeable and associated with carbonates (soluble or labile fraction). In this fraction the metals are weakly bound to the sediment, and imply greater environmental risk since they are more available for the aquatic system. The RAC was determined based on the percentage of the total metal content that was present in the first sediment fraction (soluble or labile fraction). Percentages of $1-10 \%$ represent low risk, $11-30 \%$ medium risk and $31-50 \%$ high risk $^{34,35}$.

As shown in Fig. 5, Al was found in the soluble fraction in the affluent of 
Cogotí and Recoleta reservoirs in concentrations ranging from 0.98 to $0.83 \%$. Fe was found only in the affluent of Cogotí, with a concentration of $20.82 \%$. Cu and $\mathrm{Zn}$ were found in most of the reservoirs, both in affluents and effluents. The values of $\mathrm{Cu}$ were observed in the following order Corrales $>$ Cogotí $>$ Recoleta $>$ La Paloma. Zn showed the lowest percentage in the Recoleta affluent (5.8\%), while the highest values were found in the La Paloma reservoir, $20.8 \%$ in the affluent and $15 \%$ in the effluent. Mn ranged from $69.83 \%$ in the effluent of Corrales to $5.94 \%$ in the affluent of La Paloma. These results suggest that $\mathrm{Fe}$ should be considered as medium risk only in the affluent of Cogotí, while $\mathrm{Cu}$ and $\mathrm{Zn}$ show medium risk in all the dams and both zones. Finally, Mn showed high risk in Corrales, medium risk in Recoleta and Cogotí and low risk in La Paloma.

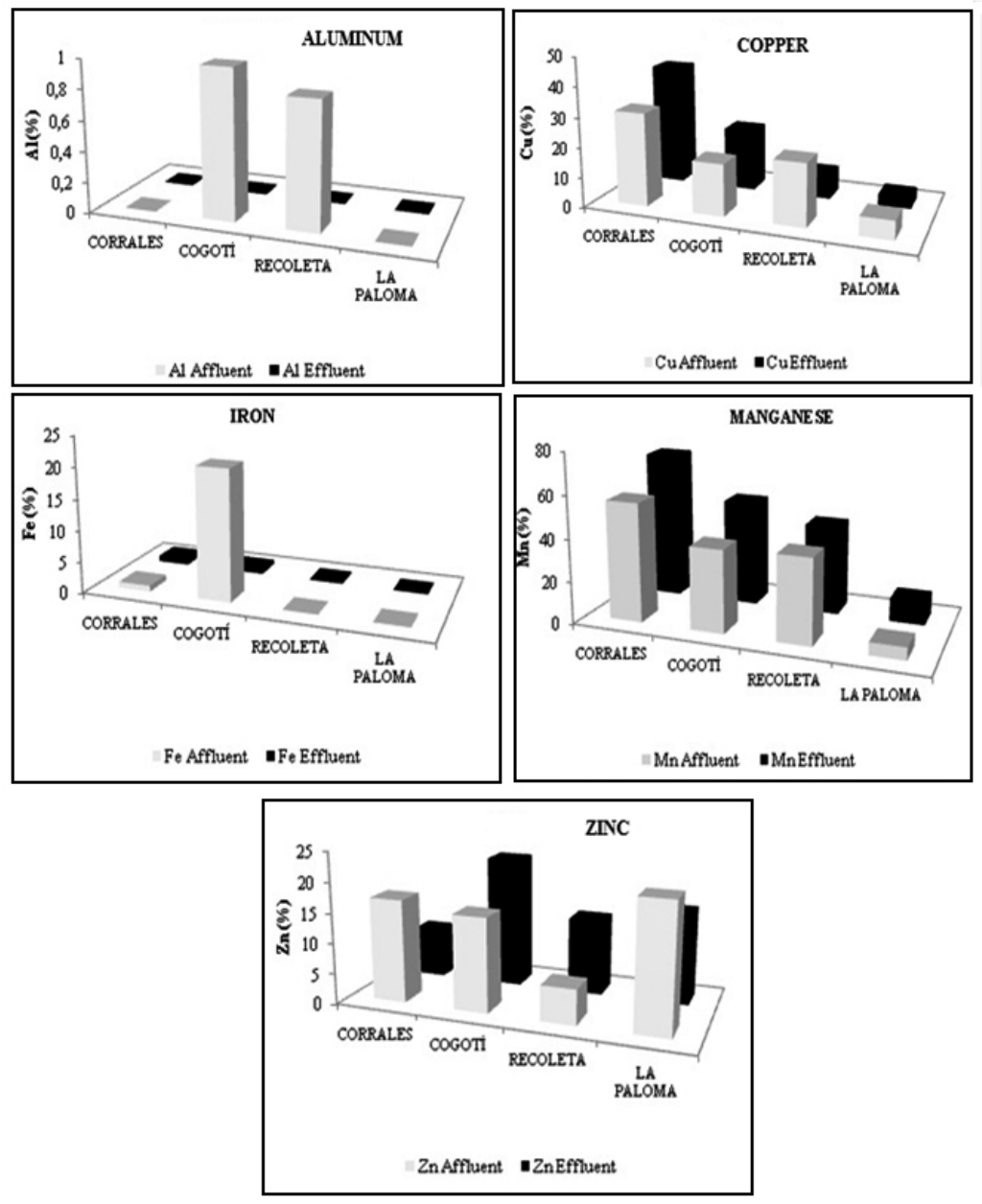

Figure 5. Percent of soluble fraction of metals of the total fraction in sediments in affluents and effluents of each dam studied.

These metals may be transferred preferentially to the water column, since higher values in the soluble fraction of these metals represent a greater percentage of the total concentration, which is due to the higher $\mathrm{pH}$ range in which these metals have greater solubility, also complemented by the oxygenation of the water. In addition, the highest concentrations of $\mathrm{Al}$ and $\mathrm{Fe}$ were found in the water, which is probably explained by the re-suspension of particles from the sediment. These two seemingly contradictory positions indicate that sediments not only act as a source of metals by solubilization or desorption, but also by re-suspension, depending on the characteristics of the elements involved and the sediment characteristics. Another study found similar behavior; $\mathrm{Al}$ and $\mathrm{Fe}$ were observed in high concentrations in the mineralogical sediment fraction, while $\mathrm{Cu}, \mathrm{Mn}$ and $\mathrm{Zn}$ would be bound to carbonates, organic matter or exchangeable fraction ${ }^{51}$.

\subsubsection{Enrichment Factor (EF)}

The total concentration of heavy metals in sediments does not represent the degree of contamination coming from either natural or anthropogenic sources, due the grain-size distribution and mineralogy ${ }^{53}$. The enrichment factor (EF) is an effective method to estimate the anthropogenic impact on sediments ${ }^{33,54}$.

$\mathrm{EF}$ is defined as follows

$\mathrm{EF}=(\mathrm{M} / \mathrm{Al}) \mathrm{s} /(\mathrm{M} / \mathrm{Al}) \mathrm{g}$
Where $(\mathrm{M} / \mathrm{Al}) \mathrm{s}$ and $(\mathrm{M} / \mathrm{Al}) \mathrm{g}$ are the ratio of metal $\mathrm{Al}$ concentration in a sample and in the reference sample, respectively. By convention an EF value ranging from 0.5 to 1.5 implies a predominantly natural origin (e.g. weathering product), while values greater than 1.5 indicate an important proportion of non-crustal materials or non-natural weathering processes (e.g. biota, point and non-point pollution $)^{53,55}$. EF values lower than 0.5 can reflect mobilization and loss of these elements relative to $\mathrm{Al}$; they could indicate an overestimation of the reference metal contents.

In this study the concentration of $\mathrm{Al}$ in the Choapa basin in the rithron site was used as reference sample (eq. 1). The site was selected because it is located at high altitude in the Andes and is near the headwaters of the river, thus having low human intervention ${ }^{56}$.

EF values of five elements in all the dams and zones indicate null human influence; nevertheless it is important to consider that some places showed values > 0.5, for example the effluent of Recoleta reservoir; $\mathrm{Al}: 0.96 ; \mathrm{Cu}: 1.00$; Fe: 0.82 and $\mathrm{Zn} 0.98$ and in the effluent of La Paloma reservoir, Mn: 1.10. The analysis using the enrichment factor in other sites confirms the assumption that $\mathrm{Cu}: 31.9$ and $\mathrm{Zn}: 22.0$ are carried into the river by mining activities in the Choapa River basin. In the Cachapoal basin there was a large enrichment factor of 17.6 for $\mathrm{Cu}$, which may be associated with $\mathrm{Cu}$-enriched ore from a treatment plant ${ }^{56}$ 


\subsubsection{Sediment toxicity}

The criteria to consider a sediment toxic are defined in the sediment quality guidelines (SQG), which provides thresholds to determine if the concentration of any of the metals present in the sediments may involve risk for aquatic organisms and consequently for human health. Threshold effect concentrations (TEC) and their probable effect concentrations (PEC) for sediment levels were reported by MacDonald et al., 2000. Where TEC correspond to the concentration below which no adverse effects are observed on benthic organisms. The PEC intends to identify the contaminant concentrations above which harmful effects on benthic organisms were expected to occur frequently ${ }^{36}$.

Threshold effect concentrations (TEC) were: for $\mathrm{Fe}=20000 ; \mathrm{Cu}=31.6$; $\mathrm{Mn}=450$ and $\mathrm{Zn}=121 \mathrm{mg} \mathrm{kg}^{-1}$ and probable effect concentration (PEC), for $\mathrm{Fe}=40000 ; \mathrm{Cu}=149 ; \mathrm{Mn}=1100$ and $\mathrm{Zn}=459 \mathrm{mg} \mathrm{kg}^{-1}$.

$\mathrm{Cu}$ concentration in affluents and effluents in all the reservoirs (Table 6) was higher than the TEC value and PEC except in the affluent of Cogotí and both zones of La Paloma. Fe concentration was higher than the TEC value in the entire reservoir and both zones except in the effluent of Recoleta; PEC was lower than the TEC values in all the dams and zones except for the effluent of Corrales. Mn concentration was higher than TEC and PEC in all the dams and in both zones, except the latter for La Paloma reservoir. $\mathrm{Zn}$ concentration was higher than TEC in all the dams and in both zones except in the effluent of La Paloma and the effluent of Recoleta, where PEC showed lower values. Of the five metals considered, $\mathrm{Cu}, \mathrm{Mn}$ and $\mathrm{Zn}$ were the elements which present the greatest toxicity to microorganisms in these aquatic systems.

\subsection{Principal component analysis (PCA)} figures.

The results of the principal components analysis is shown in the following
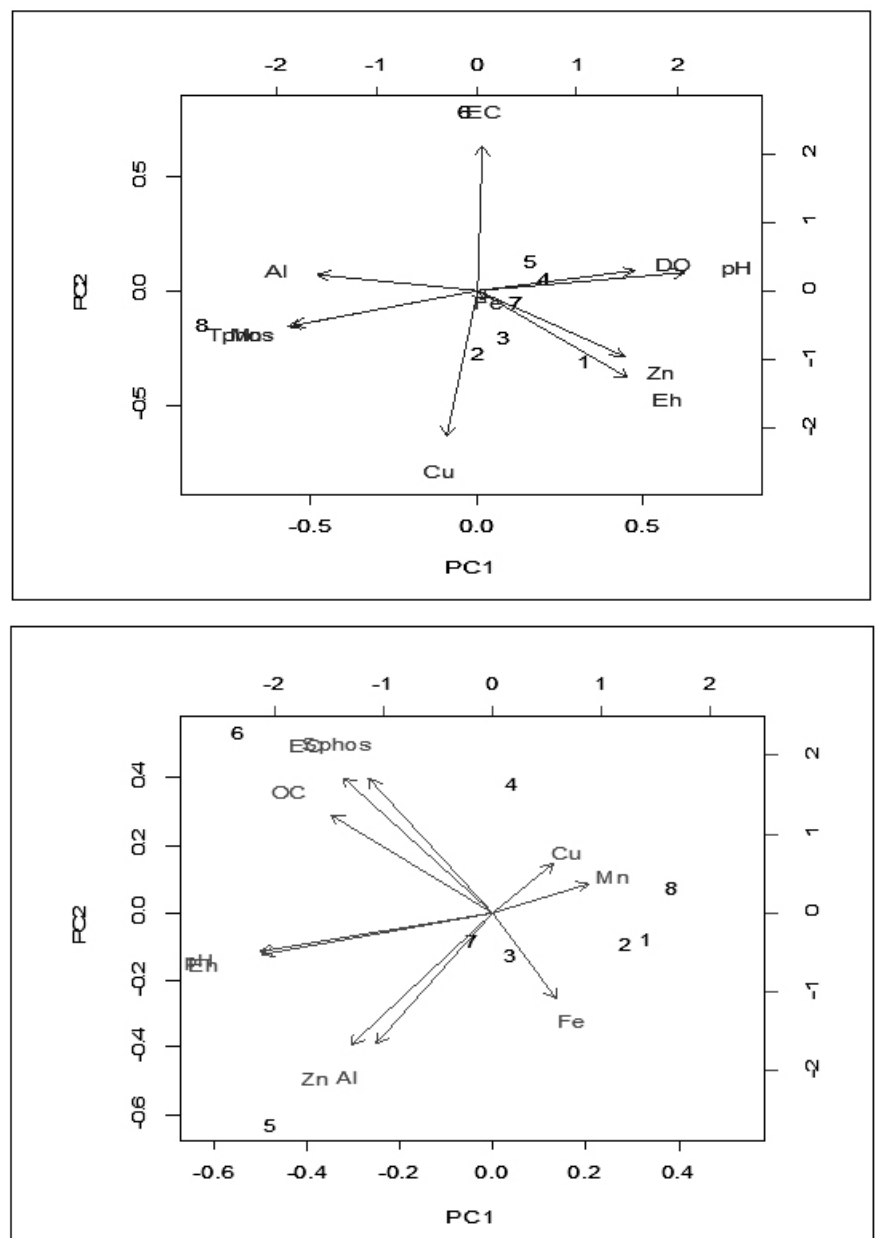

Figure 6. PCA from surface water (A) and PCA from sediment (B): Cogotí affluent (1); Cogotí effluent (2); La Paloma affluent (3), La Paloma effluent (4); Recoleta affluent (5), Recoleta effluent (6), Corrales affluent (7); Corrales effluent (8).
Figure $6 \mathrm{~A}$ and $6 \mathrm{~B}$ show that reservoirs are influenced by both metals and physical chemical characteristics of water or sediment.

In water (Figure 6A), Cogotí affluent (1) is influenced by $\mathrm{Zn}$ and Eh, Cogotí effluent (2), is influenced by $\mathrm{Cu}$, La Paloma effluent (4), is influenced by DO and $\mathrm{pH}$; Recoleta effluent (6) is influenced by EC, while Corrales effluent (8) is influenced by total P and Mn. In sediment (Figure 6B), La Paloma effluent (3) is influenced by Fe, Recoleta affluent (5) is influenced by $\mathrm{Zn}$ and Al, while Recoleta effluent (6) is influenced by OC, EC and water soluble P.

\section{CONCLUSIONS}

Five of the ten metals analyzed were detected in water and sediments (soluble and total fractions), namely $\mathrm{Al}, \mathrm{Fe}, \mathrm{Cu}, \mathrm{Mn}$ and $\mathrm{Zn}$. The total content of metals in sediment was always greater than those found in the soluble or labile fraction.

We found no differences in most of metal concentrations between affluents and effluents, indicating that the reservoirs do not act as a filter.

Metal concentrations in surface water were similar to concentrations found in other basins, except for $\mathrm{Mn}$ that had higher concentration, which may be due to the mineralogical characteristics of the reservoirs.

Metal concentrations in sediment of the reservoirs showed relatively high values for the five metals compared to the Choapa basin; probably because of the hydrodynamic conditions of the sediment.

Metal concentrations of the soluble fraction of the sediment were between $5-70 \%$ of the total fraction: $\mathrm{Mn}>\mathrm{Cu}>\mathrm{Zn}>\mathrm{Fe}>\mathrm{Al}$, showing that the solubilization of the metal depends on the sediment characteristics, especially $\mathrm{pH}$.

Results of the risk assessment code (RAC), determined by percent soluble fraction of metals in relation to total fraction of metals in sediments suggested that Fe should be considered of medium risk in the affluents of Cogotí, while $\mathrm{Cu}$ and $\mathrm{Zn}$ showed medium risk in all the dams and both zones and Mn showed medium to high risk.

The enrichment factor (EF) has shown to be an effective method to estimate the anthropogenic impact on sediments. In this study we determined the existence of five metal concentrations which have lithogenic origin.

Finally, $\mathrm{Cu}, \mathrm{Mn}$ and $\mathrm{Zn}$ concentrations in both affluents and effluents of most of the reservoirs exceeded TEC and PEC values, thus these elements should be considered as potential toxic elements for organisms.

Principal components analysis showed that dams and zones are influenced by heavy metal concentrations and physicochemical characteristics of the water or sediments.

\section{ACKNOWLEDGEMENTS}

The authors are grateful to Fondecyt Project 1100341 and Proyecto Enlace Universidad de Chile 2013. DV thanks NC 120030, Basal Grant PFB 023 and ICM P05-002.

\section{REFERENCES}

1. U. Förstner, Int J. Environ. Anal. Chem., 51, 5, (1993).

2. C. J. Vörosmarty, P. B. McIntyre, M. O Gessner, D Dudgeeon, A Prusevich, P. Green, S. Glidden, S. E. Bunn, C. A. Sullivan, C. Rendy Liermann, P. M. Davies, Nature, 467, 555, (2010).

3. J. Duffus, Pure Appl. Chem., 74, 793, (2002).

4. U. Förstner, G. T. W. Wittmann, Heavy metal pollution in the aquatic environment $2^{\text {nd }}$ ed. Springer: Berlin Germany, 1981; pp 71-109

5. K. S. Murray, Environ. Geol. 27, 54, (1996).

6. F. Prosi, Heavy metals in aquatic organism. In Metal Pollution in the Aquatic Environment F. Förstner, U. and Wittmann, eds Sprong Verlag, Berlin, 1981; pp 271-323-

7. S. M. Moalla, R. M. Awadallah, M. N. Rashed, M. E. Soltan, Hidrobiol. 364, 31, (1998).

8. D. Purves, Trace elements contamination of the environment. Elsiever Amsterdan, ; pp 3-38 1985.

9. W. Chen, S. K.Tan, J. H. Tay, Water, Air and Soil Pollution, 92, 273, 1996

10. G. G. Geesy, L. Borstad, P. M. Chapman, Water Res. 18, 233, (1984).

11. R. Vink, H. Behrentd, W. Solomon, Water Sci. Technol. 39, 215, (1999).

12. V. M. Dekov, F. Araújo, R. Van Grieken, V. Subramanian, Sci. Total Environ. 212, 89, (1998).

13. L. Sigg, M. Sturm, D. Kistler, Limnology and Oceanography, 32, 112, (1987).

14. R. Carignan, A. Tessier, Geochimand Cosmochim. Acta 52, 1179, (1988). 
15. P. Vaithiyanathan, A. Ramanathan, V. Subramantan, Water, Air and Soil Pollution, 71, 13, (1993)

16. A. K. Singh, S. 1. Hasnain, D. K. Banerjee, Environ. Geol. 39, 90, (1999).

17. S. I. Santos, C. A. B. García, E. A. Passos, E. A. Passos, J. P. Alves, J. Braz. Chem. Soc. 24, 246, (2013).

18. W. Solomons, U. Förstner, Environ Technol. Lett. 1, 506, (1980).

19. R. Baudo, H. Muntau, Chapter I. Lesser Known in-place pollutants and diffuse source problems. In Baudo, R., Giessey, J. P. and Muntau, H. Sediments Chemistry and toxicity of in place pollutants. Ann Arbor. Lewis Publisher, 1990; pp 1-50.

20. H. E. Belkin, H. M. Sparck, USA Environ. Geol., 22, (1993).

21. X-Y Wu, Y. F. Yang, Aquaculture Reserach, 41, 1377, (2010).

22. A. J. de Groot, K. H. Zschuppel, W. Salomons, Hydrobiologia, 91, 689, (1982).

23. C. M. Davidson, R. P.Thomas,S. E. McVey, R. Perala, D. Littlejohn, A. M. Ure, Analytica Chimica Acta, 291, 277, (1993).

24. A. M. Ure, P. Quevauviller, H. Muntauc, B. Griepink, International Journal of Environmental Analytical Chemistry, 51, 135, (1993).

25. D. L. Saunders, J. J. Meeuwing, A. C. J. Vincent, Conserv. Biol. 16, 30, (2002).

26. F. J. Gottgens, J. E. Evans, J. Great Lakes Res., 2, 87, (2007).

27. W. L. Graf, Water Resources Res., 35, 1305, (1999).

28. M. Dynesius, C. Nilsson, C. Science, 266, 753, (1994).

29. P. Morais, Intern. J. Limnol. 44, 105, (2008).

30. C. Nilsson, C. A. Reidy, M. Dynesius, C. Revenga, Science. 308, 405 , (2005).

31. J.G Rangel-Peraza, J. de Anda, _F. A. González-Farías, M. Rode, A. Sanhouse-García, Y. A. Bustos-Terrones, Environmental Monitoring and Assessment. 187, 134 (2015).

32. K. W. Thorton, B. L. Kimmel, F. E. Payne, eds. Reservoir Limnology: Ecological perspectives. John Wiley \& Sons, Inc., Somerset, New Jersey, 1990, pp 246-256.

33. G. Abrahim, R. Parker, Monit Assess. 136, 227, (2008).

34. Ed. A. Passon, J. C. Alves, I. S. A. Dos Santos, J. P. H. Alves, C. A. B. Garcia, A. C. Spinola Costa, Microchem. J. 96, 50, (2010).

35. G. Perin, L. Craboleda, M. Lucchese, R. Cirillo, I. Dotta, I., M. Zanette, Orio, Heavy metals speciation in the sediments of Northen Adriatic sea-a new approach for environmental toxicity determination: in Lekkas TD, editor: Heavy metal in the enviroment, 2010, pp. 45-46.

36. D. D. MacDonald, C. Ingersoll, T. Berger, Arch. Environ. Contam. Toxicol., 39, 20, (2000).

37. H. Mülhauser, L. Soto, R. Zahradnik, Int. J. Environ of Anal. Chem., 28, $215,(1987)$.

38. S. I. Simpson, G. E. Batley, A. A. S. Charlston, J. L. Dtauber, C. K. King, J. C. Chapman, R. V. Hyne, S. A. Gale, A. C. Roach, W. A. Maher, J. Sharyan. J, Handbook for Sediment Quality Assessment, (CSIRO Bangor, NSW), 2005; pp 9-19.

39. L. C. Blackemore, P. L. Scarle, B. K. Daly, B. K. In Methods for Chemical of Analysis of Soils N. Z. Soil Bureau Scientific Report, 1987, pp 18-34.

40. A. Sadzawka, M. A. Carrasco, R. Grez, M. L. Mora, H. Flores, A. Neuman, A. Métodos de Análisis de Suelos. Instituto de Investigaciones Agropecuarias (INIA). Serie Actas INIA N ${ }^{\circ} 34,2006$; pp 59-79.

41. R Core Team. R (2013). A language and environment for statistical computing. R Foundation for Statistical Computing, Vienna, Austria. URL http://www. R-project.org/. .

42. Broberg, A., McMasters, S. Uptake of copper and cadmium by tubificids worms (oligochaeta) in different freshwater sediments. En: Heavy Metals in the Hydrological Cycle. M.Astruc. \& J. N. Lester (Eds). Selper Ltd Lndon pp 265-272 (1988).

43. F. Burriel Marti, F. Lucena-Conde, S. Arribas-Jimeno, J. Hernadez Méndes. Química Analítica Cualitativa (Décimo Sexta Edición) (Editorial PARANINFO) Madrid, España. cap. XIX y XX, 2003.

44. G. Klaver, B. Van Os., Ph. Negrel, E. Petelet-Girand, Environ. Pollut, 148, $718,(2007)$.

45. S. Wang, W. Rui, L. Xing, Earth Sci. Front. 981, 29, (2002).

46. N. Roig, J. Sierra, M. Nadal, I. Moreno-Garrido, E. Nieto, M. Hampel, E. Perez Gallego, M. Schuhmacher, J. Blasco. Science of the Total Enviroment, 503-504, 269, (2015).

47. DGA (Dirección General de Aguas). Caracterización de Sedimentos Fluviales y su Relación con la Calidad del agua, 2008, pp 1-80.

48. Q. Yongmin, Y. Yang, G. Jiaguang, Z. Jiangang. Mar. Pollut. Bull. 68, 143 (2913).

49. A. Tessier, P. G. C. Cambell, M. Bisson, M. Anal. Chem., 51, 844, (1979).
50. I. Ahumada, A. Maricán, M. Retamal, C. Pedraza, C., L. Ascar, M. A. Carrasco, P. Richter, P, J. Braz. Chem. Soc. 21, 721, (2010).

51. S. V. Copaja, M. X. Molina, R. M. Tessada, J. Chil. Chem. Soc., 57, 1986, (2014).

52. R. Segura, V. Arancibia, M. C. Zúñiga, P. Pastén. Journal of Geochemical Exploration, 91, 71. (2006)

53. Gu Y. G., Wang Z-H., Lu S-h., Jiang, S-J., Nu, D-S., Zu, Y-H. Environmental Pollution 163, 248 (2012).

54. Prego, R., Cobelo-Garcia, A. Twentieth century overview of heavy metals in the Galician Rios (NW Iberian Peninsule). Environmental Pollution 121, 1425 (2003).

55. Zhang J.; Liu C. L. Estuarine, Coastal and Shelf Science, 54, 1051, (2002).

56. S. V. Copaja, G. Díaz, R. Toro, R. M. Tessada, P. Miranda, J. R. Morales, J. Chil Chem Soc. 57, 1400, (2012) 